\title{
Analysis of the National Ignition Facility Ignition Hohlraum Energetics Experiments
}

R. P. J. Town, M. D. Rosen, P. A. Michel, L. Divol, J. D. Moody, G. A. Kyrala, M. B. Schneider, J. L. Kline, C. A. Thomas, J. L. Milovich, D. A. Callahan, N. B. Meezan, D. E. Hinkel, E. A. Williams, R. L. Berger, M. J. Edwards, L. J. Suter, S. W. Haan, J. D. Lindl, S. Dixit, S. H. Glenzer, O. L. Landen, E. I. Moses, H. A. Scott, J. A. Harte, G. B. Zimmerman

December 1, 2010

Physics of Plasmas 
This document was prepared as an account of work sponsored by an agency of the United States government. Neither the United States government nor Lawrence Livermore National Security, LLC, nor any of their employees makes any warranty, expressed or implied, or assumes any legal liability or responsibility for the accuracy, completeness, or usefulness of any information, apparatus, product, or process disclosed, or represents that its use would not infringe privately owned rights. Reference herein to any specific commercial product, process, or service by trade name, trademark, manufacturer, or otherwise does not necessarily constitute or imply its endorsement, recommendation, or favoring by the United States government or Lawrence Livermore National Security, LLC. The views and opinions of authors expressed herein do not necessarily state or reflect those of the United States government or Lawrence Livermore National Security, LLC, and shall not be used for advertising or product endorsement purposes. 


\section{Analysis of the National Ignition Facility Ignition Hohlraum Energetics Experiments*}

R. P. J. Town,${ }^{1}{ }^{\dagger}$ M. D. Rosen,${ }^{1}$ P. A. Michel,${ }^{1}$ L. Divol,${ }^{1}$ J. D. Moody,${ }^{1}$ G. A. Kyrala,${ }^{2}$ M. B. Schneider, ${ }^{1}$ J. L. Kline,${ }^{2}$ C. A. Thomas,${ }^{1}$ J. L. Milovich, ${ }^{1}$ D. A. Callahan,${ }^{1}$ N. B. Meezan, ${ }^{1}$ D. E. Hinkel, ${ }^{1}$ E. A. Williams, ${ }^{1}$ R. L. Berger,${ }^{1}$ M. J. Edwards, ${ }^{1}$ L. J. Suter,${ }^{1}$ S. W. Haan, ${ }^{1}$ J. D. Lindl, ${ }^{1}$ E. L. Dewald, ${ }^{1}$ S. Dixit,${ }^{1}$ S. H. Glenzer, ${ }^{1}$ O. L. Landen, ${ }^{1}$ E. I. Moses,${ }^{1}$ H. A. Scott,${ }^{1}$ J. A. Harte,${ }^{1}$ and G. B. Zimmerman ${ }^{1}$

${ }^{1}$ Lawrence Livermore National Laboratory, P.O. Box 808, Livermore, California 94551-0808, USA

${ }^{2}$ Los Alamos National Laboratory, Los Alamos, New Mexico 87545, USA

(Dated: January 5, 2011) 


\begin{abstract}
A series of forty experiments on the National Ignition Facility (NIF) [E. I. Moses et al., Phys. Plasmas 16, 041006 (2009)] to study energy balance and implosion symmetry in reduced- and fullscale ignition hohlraums was shot at energies up to 1.3 MJ. This paper reports the findings of the analysis of the ensemble of experimental data obtained that has produced an improved model for simulating ignition hohlraums. Last year the first observation in a NIF hohlraum of energy transfer between cones of beams as a function of wavelength shift between those cones was reported [P. Michel, et al, Phys of Plasmas, 17, 056305, (2010)]. Detailed analysis of hohlraum wall emission as measured through the laser entrance hole (LEH) has allowed the amount of energy transferred versus wavelength shift to be quantified. The change in outer beam brightness is found to be quantitatively consistent with LASNEX [G. B. Zimmerman and W. L. Kruer, Comments Plasma Phys. Control. Fusion 2, 51 (1975)] simulations using the predicted energy transfer when possible saturation of the plasma wave mediating the transfer is included. The effect of the predicted energy transfer on implosion symmetry is also found to be in good agreement with gated x-ray framing camera images. Hohlraum energy balance, as measured by x-ray power escaping the LEH, is quantitatively consistent with revised estimates of backscatter and incident laser energy combined with a more rigorous non-local-thermodynamic-equilibrium atomic physics model with greater emissivity than the simpler average-atom model used in the original design of NIF targets.
\end{abstract}

*Paper BI2 4, Bull. Am. Phys. Soc. 55, 21 (2010)

$\dagger$ Electronic address: town2@llnl.gov 


\section{INTRODUCTION}

The National Ignition Campaign (NIC) is an integrated experimental and computational program to tune an inertial confinement fusion target to the required conditions necessary to achieve indirectly-driven ignition on the National Ignition Facility (NIF)[1]. The first phase of the NIC is to verify that the energetics of the hohlraum meet ignition requirements. The primary goal of the hohlraum energetics experiments[2] was to demonstrate: 1) sufficient laser coupling to the hohlraum so that enough laser energy is available for x-ray drive; 2) high enough x-ray drive to implode a stable shell fast enough; and 3) symmetry control. An important secondary goal was to refine our radiation-hydrodynamic and laser-plasma interaction design tools based on the results of these experiments.

Analysis of the hohlraum energetics experiments has led to three important changes to the prior physics model, which was based on experiments performed at the Nova[3] and OMEGA[4] laser facilities. First, the x-ray drive measurements required a more emissive nonlocal-thermodynamic-equilibrium (NLTE) atomic physics model and near classical electron heat transport. Second, experiments demonstrated cross-beam transfer of laser energy which has been included using a semi-empirical model. Third, data suggested that the backscatter on the $23.5^{\circ}$ quad scaled differently than on the measured $30^{\circ}$ quad.

This paper is organized as follows. We briefly review the design tools in section II and the experimental setup in section III. The paper details the experimental evidence and comparison to the computational models for the drive (section IV), symmetry (section V) and coupling results (section VI). Finally, section VII summarizes the results of the hohlraum energetics campaign that have validated the hohlraum platform for ignition tuning experiments.

\section{SIMULATION METHODOLGY}

There are two classes of simulation that are routinely performed in support of NIF experiments. The first, termed pre-shot simulations, applies the point design model to design the experiment, make predictions of diagnostic signatures (to assist in experimental configuration), and construct "play books" to guide modifications of future experiments. These simulations use generic target parameters and the requested laser-pulse shape with an esti- 
mate of backscatter removed. The second simulation type are termed post-shot simulations. These simulations deploy the point design model and alternate physics models to the actual fielded target and use the as-shot laser pulse with the measured backscatter removed. Simulated diagnostic signatures are generated and compared to experiment. Different physics models are evaluated and compared against the experimental database and, if a compelling case can be made, then the physics model of the point design is updated.

In this paper we report on simulations using the two-dimensional axisymmetric radiationhydrodynamics code LASNEX[5]. The baseline model was validated during the Nova technical contract and subsequently refined by experiments on the OMEGA laser system[6][7]. This model uses an in-line NLTE average atom model (XSN) to generate multigroup emissivity and opacity data for the high-Z hohlraum wall[8]. The quotidian equation of state $(\mathrm{EOS})[9]$ is used for hohlraum materials and gases at low temperature; at high temperature, the XSN NLTE equation of state is used. The electron heat transport uses Spitzer conductivity, but limited to $f=0.05$ of the free streaming value. The capsule materials use more sophisticated LTE tabular opacities and EOS models. This model was used to develop the NIF ignition point designs[10] and to set the NIF laser requirements.

We have recently developed a new model for hohlraums called the high flux (HF) model that incorporates two physics improvements[11, 12]. The first improvement is to the atomic physics model of the hohlraum wall. It has recently been shown[13] that the XSN model used in the Nova model was not as emissive as more detailed NLTE models such as SCRAM[14]. It is worth noting that the differences due to emissivity models becomes more apparent at larger scale. Hohlraum energetics is generally dominated by wall loss, which scales as the hohlraum area. However, energy is also stored in the coronal plasma, which scales as the hohlraum volume. The ratio between the energy stored in the corona to the wall loss thus scales as ratio of the hohlraum volume to the area which is proportional to the hohlraum scale size. A more emissive atomic physics model reduces the energy stored in the coronal plasma, which is more significant at NIF scale where up to $40 \%$ of the energy is stored in the corona as opposed to $20 \%$ at OMEGA scale $[12,13]$. With the advent of faster computers it has become possible to routinely run NLTE atomic physics models based on the detailed configuration accounting (DCA) approach[15] that include many thousands of levels compared to the tens of levels used in average atom models such as XSN. In particular the inclusion of dielectric recombination allows the re-population of active levels which enables 
more efficient radiation. The second improvement increases the flux limiter to $f=0.15$ that better matches the temperature distribution of more sophisticated non-local electron transport models (see ref[12] for a comparison of the non-local electron transport model to various flux-limiters).

\section{EXPERIMENTAL SETUP}

The NIF hohlraum energetics campaign[2] fielded two sizes of hohlraums and five different laser pulses (Fig. 1). The smaller emulator-scale hohlraum used laser pulses with energies from $500 \mathrm{~kJ}$ to $800 \mathrm{~kJ}$ with pulse lengths from 11-ns to 19-ns. These sub-scale hohlraums were designed to reproduce the hohlraum plasma conditions of the 1.3MJ ignition design while operating at lower laser energies. The larger ignition-scale hohlraum used laser energies from $800 \mathrm{~kJ}$ to $1.3 \mathrm{MJ}$ with pulse lengths of $20-\mathrm{ns}$. The initial two experiments used a hydrocarbon fill gas and were shot at room temperature. Subsequent experiments operated at cryogenic temperatures and were filled with either pure helium, or a hydrogen-helium mixture. The choice of hohlraum gas density is based on the desire to achieve adequate time-dependent x-ray drive symmetry and limit hydrocoupling. High hohlraum gas density limits hohlraum wall motion ensuring time-dependent x-ray drive symmetry, but potentially introducing capsule asymmetries by the coupling of capsule to the hohlraum. At the other extreme low hohlraum gas density allows hohlraum wall motion that introduces time-dependent x-ray drive asymmetry, but reduces hydrocoupling. Design calculations were performed and an optimal gas density was found. Typically the hohlraum gas was filled to create an electron number density of $4.5 \%$ of the critical density for $351 \mathrm{~nm}$ light (equivalent to $4 \times 10^{20} \mathrm{~cm}^{-3}$.) A few experiments were performed at lower gas densities and are included in the dataset reported here. The hohlraum wall was manufactured from either pure Gold, or a Gold-Boron mixture. The hohlraums contained a so-called "symcap" plastic capsule[16]. The ablator of these capsules was identical to the ignition capsule, but the deuterium-tritium ice layer was replaced by a plastic layer of equivalent mass to ensure similar hohlraum plasma conditions and implosion trajectory to the ignition capsule. The capsules were filled with pure helium, or a deuterium-helium mixtures at a density of $8.3 \mathrm{mg} / \mathrm{cm}^{3}$ which allowed the capsule to converge to around one-tenth the original capsule radius.

The NIF's 192 beams are arranged into 48 quads. These quads are further arranged into 
inner and outer cones. The inner cone consists of eight quads at $23.5^{\circ}$ and eight quads at $30^{\circ}$ relative to the hohlraum axis of rotation. The outer cone consists of 16 quads at $44.5^{\circ}$ and a further 16 quads at $50^{\circ}$. The inherent inner cone fraction (defined as the inner cone power divided by the total power) of the NIF is thus one-third.

For the initial NIF experiments the laser power that is backscattered out of the hohlraum was measured on one $30^{\circ}$ inner-cone quad and one $50^{\circ}$ outer-cone quad. The full-aperture backscatter station (FABS) measures the energy, power, and spectrum of the stimulated Raman scattered (SRS), and stimulated Brillouin scattered (SBS) light that is reflected directly back into the final optics. The SRS and SBS are measured with an error of $\pm 17 \%$ and $\pm 20 \%$ respectively. The near backscatter imager (NBI) measures SRS and SBS light in an $f / 4$ cone around the quad[17] with an error of $\pm 14 \%$. Since we do not self-consistently calculate laser-plasma instability processes in our radiation hydrodynamic simulations we remove the measured backscattered light from the incident laser beams. We have typically assumed that the undiagnosed $23.5^{\circ}$ and $44.5^{\circ}$ quads have the same backscatter as the $30^{\circ}$ and $50^{\circ}$ respectively. In addition to being an input into our post-shot simulation the backscatter diagnostic also provides information about the temperature and density of the plasma. An indirect measure of laser-plasma instabilities is obtained from the hard xrays $(>20 \mathrm{keV})$ generated by hot electrons that are detected by the filter-fluorescer array FFLEX[18].

The principal x-ray drive diagnostic, DANTE, is an absolutely calibrated, time-resolved 18-channel x-ray diode array that measures the x-ray flux and spectrum from $70 \mathrm{eV}$ to 10 $\mathrm{keV}$ emitted through the LEH at an angle of $37^{\circ}$ to the hohlraum axis[19]. The error in the total flux is typically $\pm 5 \%$ during the peak and $\pm 10 \%$ in the foot of the laser pulse.

Two static x-ray imagers (SXI) produce time-integrated images of the inside of the hohlraum wall as viewed through the LEH at an angle of $18^{\circ}$ and $19^{\circ}$ to the hohlraum axis[20][21]. The images provide information on the backlit size of the LEH and the positions and intensities of the laser beams interaction with the hohlraum wall. The SXI is sensitive to x-ray energies in the $3-5 \mathrm{keV}$ range with a spatial resolution of $60 \mu \mathrm{m}$.

The final diagnostic that we will compare to simulations is the gated x-ray detector (GXD), which takes multiple time-resolved images of the self-emission of the imploding capsule through a hole in the side of the hohlraum wall[22]. The GXD has a spatial resolution of $10 \mu \mathrm{m}$ and temporal resolution of 70 -ps. The shape of the imploded capsule obtained from 
the GXD is a sensitive measure of the symmetry of the x-ray drive.

\section{X-RAY DRIVE}

The Nova and HF model had previously been compared[23] to the initial NIF vacuum hohlraum experiments performed in 2009. It was shown that the Nova model consistently underestimated the Dante flux, whereas the HF model reproduced the peak Dante drive for laser energies from $150 \mathrm{~kJ}$ to $600 \mathrm{~kJ}$. Unlike the energetics experiments described here, these hohlraums did not contain a capsule and were not filled with gas.

The experimental and simulated Dante flux as a function of time is shown in Fig. 2 for an ignition-scale hohlraum driven by a 1.0MJ drive (shot N091204). The Nova model has a much lower drive throughout the peak than the experimental observation. The HF model has a significantly higher total flux during the peak that matches the experiment within the experimental error bar of $5 \%$. Similar behavior is seen at emulator- and ignition-scale driven from $500 \mathrm{~kJ}$ to $1.3 \mathrm{MJ}$. To summarize this we have compared the peak x-ray flux over the complete hohlraum dataset from 2009 (circles) and the recent 2010 experiments (diamonds) and plotted the results of the simulated value against the experimentally measured one in Fig. 3. Good agreement between the simulation and experiment corresponds to the dashed oneto-one line. The Nova model (open blue circles) is consistently below the experimental value and falls below the line, whereas the HF model (filled red circles) is within the experimental error bars for all the experiments.

Fig. 4 shows the experimental and simulated Dante spectrum at the time of peak flux for the same 1.0 MJ shot. The Nova model has substantially less flux emitted at higher photon energies compared to the experiment. The HF model (shown in red) reproduces the experimentally measured increase in flux around an energy of $2.0 \mathrm{keV}$ that is associated with the M-band radiation of Gold. The radiation above $1.8 \mathrm{keV}$ has been found to be a source of preheat that requires the addition of Germanium dopant in the capsule ablator. This trend of higher observed x-ray preheat than the Nova model is shown in Fig. 5, which plots the fraction of radiation above $1.8 \mathrm{keV}$ to the total x-ray radiation at the time of peak x-ray flux. The HF model preheat fraction is slightly higher than the experimental observation. Based on these findings the ignition specification dopant fraction has been revised to a higher value. 


\section{SYMMETRY}

One of the most important findings of the hohlraum energetics campaign was the demonstration of cross-beam power transfer between the outer and inner cones of laser beams. This ability to vary the inner cone fraction was successfully used to tune the implosion symmetry of the capsule[24]. It was predicted by Kruer et al.[25] that power could be transferred between laser beams via induced Brillouin scattering and was experimentally observed by Kirkwood et al.[26] on the Nova laser facility. In 2009, Michel et al.[27] described a new model coupled to LASNEX that theoretically demonstrated the ability to tune the symmetry of the imploded ignition capsule. Last year Michel et al.[28] reported on a simplified linear model that could be routinely applied to LASNEX simulations for multiple times during the laser pulse. The amount of power transfer between the inner and outer beams can be controlled by varying the wavelength separation between the cones $\Delta \lambda=\lambda_{\text {inner }}-\lambda_{\text {outer }}$. The typical wavelength shifts $(\Delta \lambda)$ in the infra-red (where $\lambda=1.0 \mu m$ ) are between 1.5 and 8.5 $\AA$. In our post-shot simulations of these experiments we now take account of the predicted power transfer in the following manner. First we generate plasma maps from simulations that use the as-shot target parameters and the incident laser powers. We then calculate the linear kinetic coupling between all 24 laser quads that cross in the LEH region. Unlike our previous calculations we now apply a saturation amplitude to the excited ion acoustic wave. By comparison to one shot (the 1.0MJ N091204 shot described above) we choose the saturation amplitude to give power transfer consistent with the experimentally observed symmetry. We modify the incident laser pulse by this amount of power transfer and then subtract the measured backscatter from the four quads. Finally we re-run the calculation using this modified laser pulse and generate the simulated diagnostics to compare with experiment. Figure 6 shows an example of the incident laser pulse before power transfer and the laser pulse after power transfer and backscatter removal. For large wavelength separations the inner cone fraction can increase substantially as shown in Fig. 7.

We will now compare the Nova and HF model to the $\Delta \lambda$ tuning scan performed at emulator scale driven by the $660 \mathrm{~kJ} 16$-ns laser pulse. The $\Delta \lambda$ was set at $1.5 \AA, 3.0 \AA$, and $5.0 \AA$. Figure 8 shows the change in the x-ray brightness of the portion of the SXI diagnostic attributed to the $\mathrm{x}$ rays emitted from the interaction of the far outer laser beams with the hohlraum wall. Both models reproduce the reduction in the experimental brightness which 
confirms that the predicted laser power transfer from the outer cones is consistent with the experimental observation for both models. Figure 9 shows the change in the symmetry of the imploded capsule at peak brightness time. The shape of the hot spot is characterized by decomposing the $17 \%$ contour of the x-ray emission into Legendre modes [16]. The P2/P0 reflects the power balance between the inner and outer cones. A negative P2/P0 corresponds to an oblate, or pancaked implosion brought about by less x-ray drive over the waist of the capsule compared to the pole. Conversely a positive $\mathrm{P} 2 / \mathrm{P} 0$ corresponds to a prolate, or sausaged implosion. As $\Delta \lambda$ is increased and laser energy is transferred from the outer laser quads to the inner laser quads the experimental symmetry becomes more prolate. At a given $\Delta \lambda$ the Nova model has a substantially more prolate GXD image than the experiment. For example, with a $\Delta \lambda$ of $1.5 \AA$, the Nova model is almost round (-6.5\%) whereas the experiment and HF model's GXD image is very oblate (-42\%). The HF model matches the absolute experimental symmetry and the change in symmetry with power transfer.

The HF model creates a more oblate implosion than the Nova model for two reasons. First, the HF model is more emissive than the Nova model and so the outer laser beams, which have a short path from the LEH to the hohlraum wall, convert laser energy more effectively into x rays than the Nova model. The capsule "sees" more x rays from the pole in the HF model than the Nova model. Second, the HF model has a cooler hohlraum plasma than the Nova model. As the inner cone laser beams propagate from the LEH across to the mid-plane of the hohlraum they are absorbed more effectively by the HF model's cooler plasma, thus reducing the x-ray emission at the hohlraum wall. The capsule "sees" reduced $\mathrm{x}$ rays from the waist in the HF model. It should be noted that the inner cone laser beams would also benefit from the increased emissivity of the HF model, however the inner beams' longer path length to the hohlraum wall reduces the laser energy directly deposited in the wall and thus reduces the effect of the more emissive HF model. The net effect of enhanced pole emission, and reduced waist emission leads to a more oblate capsule implosion for the HF model than the Nova model. Therefore, achieving a symmetric implosion in the current ignition hohlraum design using the HF model requires a higher inner cone fraction than the Nova model. Using the HF model a design study to optimize the aspect ratio of the hohlraum to reduce the amount of laser power transfer has been undertaken and will be experimentally demonstrated next year.

It is worth noting that the difference in the hohlraum plasma temperature between the 
Nova and HF models that plays an important role in creating the more oblate implosion in the HF model is independently confirmed by comparison of the simulated SRS spectra to the experimental one. For example, at 19ns the Nova model's wavelength of peak gain is $640 \mathrm{~nm}$ compared to $585 \mathrm{~nm}$ for the HF model and the experimentally-measured wavelength of peak reflectivity of 580nm (see [29] for a more detailed comparison.)

\section{LASER COUPLING}

As the wavelength separation between the inner and outer cones was increased to tune the symmetry the peak x-ray flux measured by Dante decreased (see the black squares in Fig. 10). The measured $30^{\circ}$ quad SRS backscatter energy remained constant with increased $\Delta \lambda$ despite an increase in laser energy for the $30^{\circ}$ quad (see blue diamonds in Fig. 11). Our post-shot simulations which remove the measured $30^{\circ}$ SRS backscatter energy from both the $30^{\circ}$ quad and the $23.5^{\circ}$ quad did not reproduce this decrease in x-ray drive with $\Delta \lambda$. However, the FFLEX diagnostic showed an increase in hot electrons with increased $\Delta \lambda$. By examining the SRS spectra of these experiments a hot electron temperature of $17 \mathrm{keV}$ was inferred. This temperature was used to constrain the FFLEX two-temperature fits of hot electron energy versus hot electron temperature and allow an estimate of the total SRS energy to be obtained from the Manley-Rowe relations. Performing this analysis showed a large increase in the total SRS backscatter energy with $\Delta \lambda$ as shown by the black squares in Fig. 11. The overall coupling efficiency of laser light into the hohlraum thus decreased from $96 \%$ at $1.5 \AA$ to $86 \%$ at $5.0 \AA$. We have attributed this additional SRS backscatter to the undiagnosed $23.5^{\circ}$ quad. When we subtract these revised $23.5^{\circ}$ SRS backscatter energies from the $23.5^{\circ}$ quad we found that both models reproduce the experimental reduction in peak x-ray flux with increased $\Delta \lambda$ as shown by the open blue circles and filled red circles in Fig. 10. As discussed in section IV the Nova model's peak flux is lower than the HF model and the experiment for all $\Delta \lambda \mathrm{s}$.

Based on these experiments a simplified NBI system has recently been added to one of the $23.5^{\circ}$ quads to directly measure the SRS energy backscattered from the $23.5^{\circ}$ quads. Initial results from this diagnostic have confirmed that the SRS on the $23.5^{\circ}$ quads scales differently than the $30^{\circ}$ quad with $\Delta \lambda$. For large $\Delta \lambda$ the SRS from the $23.5^{\circ}$ quad is typically a factor of two higher than the $30^{\circ}$ quad. Prior to the installation of the $23.5^{\circ}$ 
quad backscatter diagnostic the SRS inferred from the FFLEX measurement was used to determine the overall coupling efficiency into the hohlraum. Fig. 12 shows the coupling efficiency (defined as the ratio of the laser energy in the hohlraum to the incident laser energy) as function of incident laser energy. In ignition-scale hohlraums driven at 1.0 to 1.3MJ the laser coupling efficiency is around $88 \%$ in line with ignition requirements.

\section{CONCLUSIONS}

In summary, we have compared the Nova model and HF model to the NIF hohlraum energetics experiments and found that the HF model reproduces the experimental signatures better than the Nova model. The Nova model showed too low an x-ray drive with too little x-ray preheat fraction. The HF model matched the measured total Dante flux within the experimental error bars for all of the hohlraum energetic experiments. Only the HF model replicated the measured Dante x-ray spectrum, in particular capturing the increased emission around the Gold M-band feature. We have deployed the cross-beam transfer script to both models and found that both models show the observed reduction in x-ray brightness for the outer laser quads. However, only the HF model matches the measured absolute symmetry level of the imploded capsule. This has been attributed to the HF model's cooler hohlraum plasma conditions which lead to higher absorption of the inner quad than the Nova model thus reducing the drive over the waist of the capsule. The cooler plasma also explains the observed SRS spectra. Finally, we have revised the amount of laser energy that we subtract to take account of backscatter based on a careful analysis of the hot-electron diagnostic, which has recently been confirmed by a direct backscatter measurement.

Based on the results described in this paper we have updated our point design model to the HF model. We predicted that at $1.3 \mathrm{MJ}$ in an ignition hohlraum we would have a peak x-ray drive of $14.3 \mathrm{TW} / \mathrm{sr}$ (corresponding to an internal drive temperature of $305 \mathrm{eV}$ ) with a pre-heat fraction of $20 \%$ that would lead to a $20 \%$ prolate implosion at a $\Delta \lambda=6 \AA$. The recent 1.3MJ experiment (N101102) had a peak x-ray flux of $13.7 \pm 0.7 \mathrm{TW} / \mathrm{sr}$ with a preheat fraction of $21 \%$ and a $25 \%$ prolate implosion. The laser coupling efficiency to the hohlraum was measured at $88 \%$. 


\section{Acknowledgments}

LLNL-JRNL-463439. This work performed under the auspices of the U. S. Department of Energy by Lawrence Livermore National Laboratory under Contract No. DEAC52-07NA27344 and by Los Alamos National Laboratory under Contract No. DE-AC52$06 \mathrm{NA} 25396$.

[1] E. Moses, R. Boyd, B. Remington, C. Keane, and R. Al-Ayat, Phys. Plasmas 16, 041006 (2009).

[2] N. B Meezan, L. J Atherton, D. A Callahan, E. L Dewald, S Dixit, E. G Dzenitis, M. J Edwards, C. A Haynam, D. E Hinkel, O. S Jones, O Landen, R. A London, P. A Michel, J. D Moody, J. L Milovich, M. B Schneider, C. A Thomas, R. P. J Town, A. L Warrick, S. V Weber, K Widmann, S. H Glenzer, L. J Suter, B. J Macgowan, J. L Kline, G. A Kyrala, and A Nikroo, Phys. Plasmas 17, 056304 (2010).

[3] E. M. Campbell, Laser Part. Beams 9, 209 (1991).

[4] T. R. Boehly, D. L. Brown, R. S. Craxton, R. L. Keck, J. P. Knauer, J. H. Kelly, T. J. Kessler, S. A. Kumpan, S. J. Loucks, S. A. Letzring, F. J. Marshall, R. L. McCrory, S. F. B. Morse, W. Seka, J. M. Soures, C. P. Verdon, Opt. Commun. 133, 495 (1997).

[5] G. B. Zimmerman and W. L. Kruer, Comments Plasma Phys. Control. Fusion 2, 51 (1975).

[6] J. Lindl, Phys. Plasmas 2, 3933 (1995).

[7] J. Lindl, P. Amendt, R. Berger, S. Glendinning, S. Glenzer, S. Haan, R. Kauffman, O. Landen, and L. Suter, Phys. Plasmas 11, 339 (2004).

[8] See National Technical Information Service Document No. UCRL52276 (W. A. Lokke and W. H. Grasberger, Report No. UCRL52276, 1977). Copies may be ordered from the National Technical Information Service, Springfield, VA.

[9] R.More, K. Warren, D. Young, and G. Zimmerman, Phys. Fluids 31, 3059 (1988).

[10] S. W. Haan, J. D. Lindl, D. A. Callahan, D. S. Clark, J. D. Salmonson, B. A. Hammel, L. J. Atherton, R. C. Cook, M. J. Edwards, S. Glenzer, A. V. Hamza, S. P. Hatchett, M. C. Herrmann, D. E. Hinkel, D. D. Ho, H. Huang, O. S. Jones, J. Kline, G. Kyrala, O. L. Landen, B. J. MacGowan, M. M. Marinak, D. D. Meyerhofer, J. L. Milovich, K. A. Moreno, E. I. 
Moses, D. H. Munro, A. Nikroo, R. E. Olson, K. Peterson, S. M. Pollaine, J. E. Ralph, H. F. Robey, B. K. Spears, P. T. Springer, L. J. Suter, C. A. Thomas, R. P. Town, R. Vesey, S. V. Weber, H. L. Wilkens, and D. C Wilson, to appear in Phys. Plasmas.

[11] M. D. Rosen, Tech. Rep. LLNL-PRES-428527 3/18/10, LLNL (2010).

[12] M. D. Rosen, H. A. Scott, D. E. Hinkel, E. A. Williams, D. A. Callahan, R. P. J. Town, L. Divol, P. A. Michel, W. L. Kruer, L. J. Suter, R. A. London, J. A. Harte, and G. B. Zimmerman, "The Role of a Detailed Configuration Accounting (DCA) Atomic Physics Package in Explaining the Energy Balance in Ignition Scale Hohlraums", to be published in HEDP (2011).

[13] L. Suter, S. Hansen, M. Rosen, P. Springer, and S. Haan, ATOMIC PROCESSES IN PLASMAS: Proceedings of the 16th International Conference on Atomic Processes in Plasmas, Monterey, California, 2009.

[14] S. Hansen, J. Bauche, C. Bauche-Arnoult, and M.F. Gu, HEDP 3, 109 (2007).

[15] H. Scott and S. Hansen, High Energy Density Physics 6, 39 (2010).

[16] G. A. Kyrala, J. Kline, S. Dixit, S. Glenzer, D. Kalantar, D. Bradley, N. Izumi, N. Meezan, O. Landen, D. Callahan, S. V. Weber, J. P. Holder, S. Glenn, M. J. Edwards, J. Koch, L. J. Suter, S. Haan, R. P. J. Town, P. Michel, O. Jones, S. Langer, J. D. Moody, E . L. Dewald, T. Ma, J. Ralph, A. Hamza, E. Dzenitis, and J. Kilkenny, "Symmetry Tuning for Ignition Capsules via the Symcap Technique" this issue.

[17] J. D. Moody, P. Datte, K. Krauter, E. Bond, P. A. Michel, S. H. Glenzer, L. Divol, C. Niemann, L. Suter, N. Meezan, B. J. MacGowan, R. Hibbard, R. London, J. Kilkenny, R. Wallace, J. L. Kline, K. Knittel, G. Frieders, B. Golick, G. Ross, K. Widmann, J. Jackson, S. Vernon, and T. Clancy, Rev. Sci. Instrum. 81, 10D921 (2010).

[18] J. McDonald, L. Suter, O. Landen, J. Foster, J. Celeste, J. Holder, E. Dewald, M. Schneider, D. Hinkel, R. Kauffman, L. Atherton, R. Bonanno, S. Dixit, D. Eder, C. Haynam, D. Kalantar, A. Koniges, F. Lee, B. MacGowan, K. Manes, D. Munro, J. Murray, M. Shaw, R. Stevenson, T. Parham, B. Van Wonterghem, R. Wallace, P. Wegner, P. Whitman, B. Young, B. Hammel, and E. Moses, Phys. Plasmas 13, 032703 (2006).

[19] E. L. Dewald, K. M. Campbell, R. E. Turner, J. P. Holder, O. L. Landen, S. H. Glenzer, R. L. Kauffman, L. J. Suter, M. Landon, M. Rhodes, and D. Lee, Rev. Sci. Instrum. 75, 3759 (2004).

[20] M. D. Landon, J. A. Koch, S. S. Alvarez, P. M. Bell, F. D. Lee, and J. D. Moody, Rev. Sci. 
Instrum. 72, 698 (2001).

[21] M. B. Schneider, O. S. Jones, N. B. Meezan, J. L. Milovich, R. P. Town, S. S. Alvarez, R. G. Beeler, D. K. Bradley, J. R. Celeste, S. N. Dixit, M. J. Edwards, M. J. Haugh, D. H. Kalantar, J. L. Kline, G. A. Kyrala, O. L. Landen, B. J. MacGowan, P. Michel, J. D. Moody, S. K. Oberhelman, K. W. Piston, M. J. Pivovaroff, L. J. Suter, A. T. Teruya, C. A. Thomas, S. P. Vernon, A. L. Warrick, K. Widmann, R. D. Wood, and B. K. Young, Rev. Sci. Instrum. 81, 10E538 (2010).

[22] G. A. Kyrala, S. Dixit, S. Glenzer, D. Kalantar, D. Bradley, N. Izumi, N. Meezan, O. L. Landen, D. Callahan, S. V. Weber, J. P. Holder, S. Glenn, M. J. Edwards, P. Bell, J. Kimbrough, J. Koch, R. Prasad, L. Suter, J. L. Kline, and J. Kilkenny, Rev. Sci. Instrum. 81, 10E316 (2010).

[23] J. L. Kline, K. Widmann, A. Warrick, R. E. Olson, C. A. Thomas, A. S. Moore, L. J. Suter, O. Landen, D. Callahan, S. Azevedo, J. Liebman, S. H. Glenzer, A. Conder, S. N. Dixit, P. Torres, III, V. Tran, E. L. Dewald, J. Kamperschroer, L. J. Atherton, Jr R. Beeler, L. Berzins, J. Celeste, C. Haynam, W. Hsing, D. Larson, B. J. MacGowan, D. Hinkel, D. Kalantar, R. Kauffman, J. Kilkenny, N. Meezan, M. D. Rosen, M. Schneider, E. A. Williams, S. Vernon, R. J. Wallace, B. Van Wonterghem, and B. K. Young, Rev. Sci. Instrum. 81, 10E321 (2010).

[24] S. H Glenzer, B. J. MacGowan, P. Michel, N. B. Meezan, L. J. Suter, S. N. Dixit, J. L. Kline, G. A. Kyrala, D. K. Bradley, D. A. Callahan, E. L. Dewald, L. Divol, E. Dzenitis, M. J. Edwards, A. V. Hamza, C. A. Haynam, D. E. Hinkel, D. H. Kalantar, J. D. Kilkenny, O. L. Landen, J. D. Lindl, S. LePape, J. D. Moody, A. Nikroo, T. Parham, M. B. Schneider, R. P. J. Town, P. Wegner, K. Widmann, P. Whitman, B. K. F. Young, B. Van Wonterghem, L. J. Atherton, and E. I. Moses, Science 327, 1228 (2010).

[25] W. L. Kruer, S. C. Wilks, B. B. Afeyan, and R. K. Kirkwood, Phys. Plasmas 3, 382 (1996).

[26] R. K. Kirkwood, B. B. Afeyan, W. L. Kruer, B. J. MacGowan, J. D. Moody, D. S. Montgomery, D. M. Pennington, T. L. Weiland, and S. C. Wilks, Phys. Rev. Lett. 76, 2065 (1996).

[27] P. Michel, L. Divol, E. A. Williams, S. Weber, C. A. Thomas, D. A. Callahan, S. W. Haan, J. D. Salmonson, S. Dixit, D. E. Hinkel, M. J. Edwards, B. J. MacGowan, J. D. Lindl, S. H. Glenzer, and L. J. Suter, Phys. Rev. Lett. 102, 025004 (2009).

[28] P. Michel, S. H. Glenzer, L. Divol, D. K. Bradley, D. Callahan, S. Dixit, S. Glenn, D. Hinkel, R. K. Kirkwood, J. L. Kline, W. L. Kruer, G. A. Kyrala, S. Le Pape, N. B. Meezan, R. Town, 
K. Widmann, E. A. Williams, B. J. Macgowan, J. Lindl, and L. J. Suter, Phys. Plasmas 17, 056305 (2010).

[29] D. E. Hinkel, M. D. Rosen, E. A. Williams, A. B. Langdon, C. H. Still, D. A. Callahan, J. D. Moody, P. A. Michel, R. P. J. Town, R. A. London, and S. H. Langer, "Stimulated Raman Scatter Analyses of Experiments Conducted at the National Ignition Facility", this issue. 


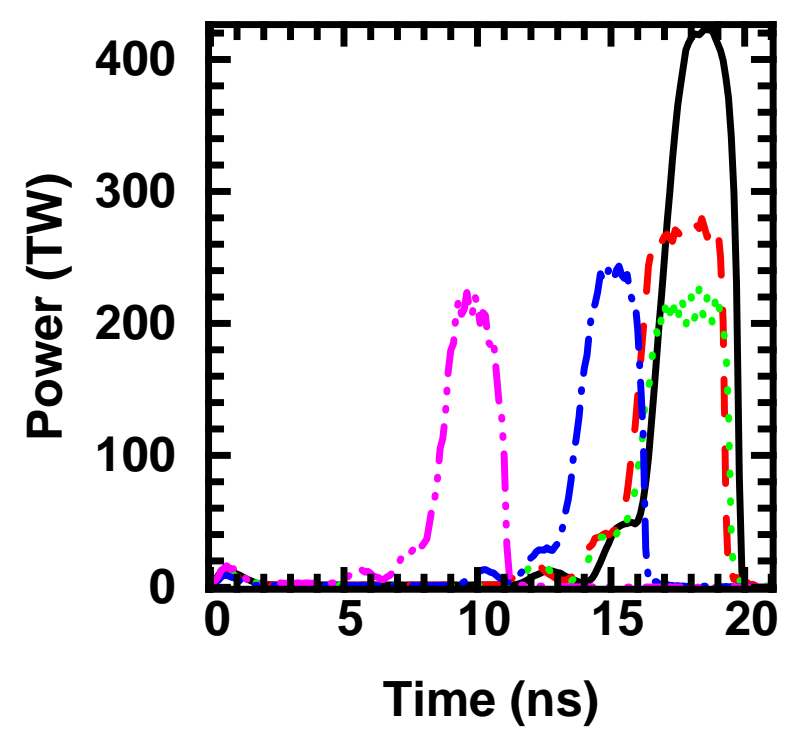

FIG. 1: (Color online) Five laser pulses with energies from 500kJ to $1.3 \mathrm{MJ}$ were fielded during the hohlraum energetics campaign.

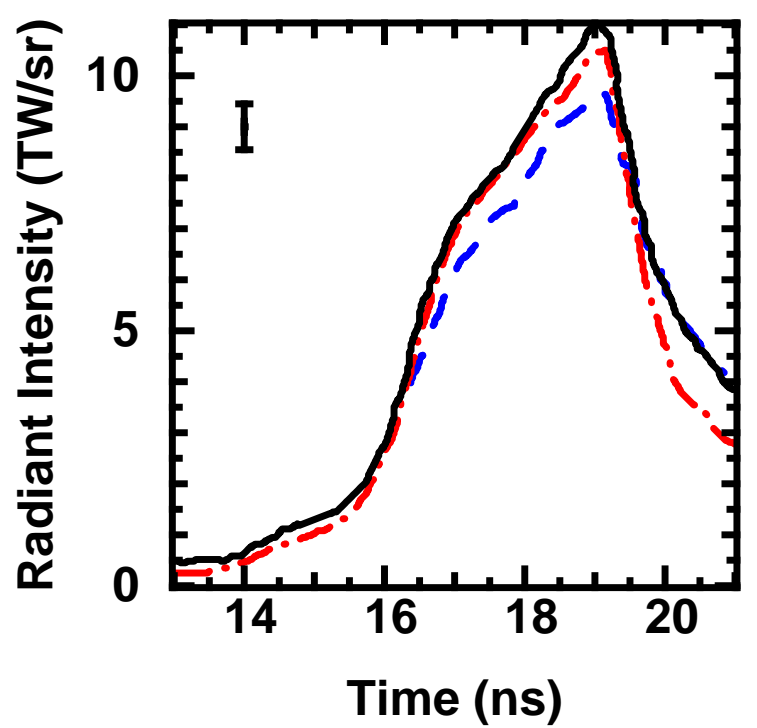

FIG. 2: (Color online) The total Dante flux as a function of time for the experiment (black solid line), HF model (red dash-dot line), and Nova model (blue dashed line) for an ignition-scale hohlraum driven with a 1.0MJ laser drive (shot N091204). 


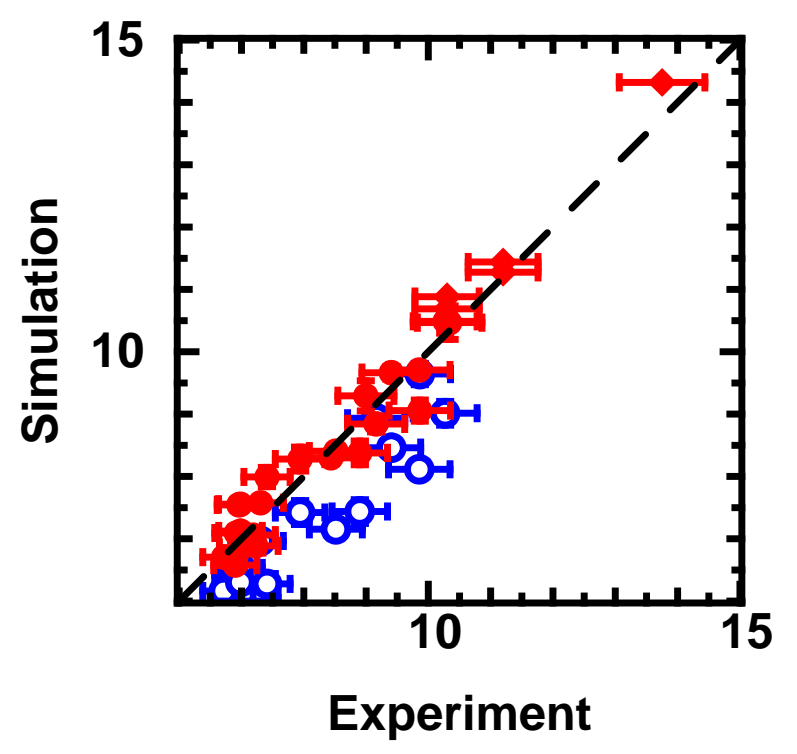

FIG. 3: (Color online) The simulated peak x-ray flux from the Nova model (blue open circles) and the HF model (red filled circles) against the experimental peak Dante flux for the 2009 experiments. Also shown, as red diamonds, are the HF model's simulations for the 2010 experiments. Good agreement between the simulation and the experiment corresponds to the dashed one-to-one line. The experimental error bars are $\pm 5 \%$.

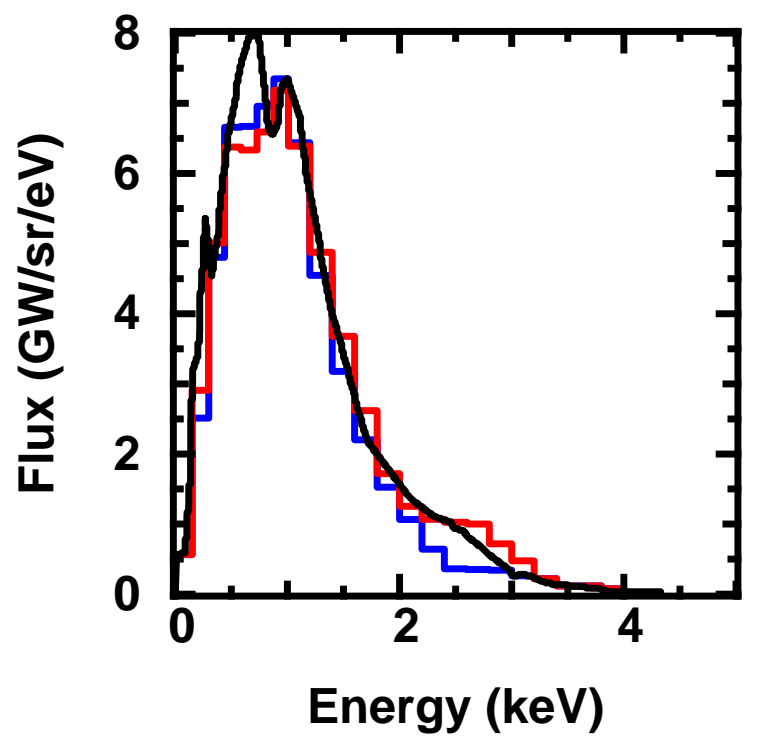

FIG. 4: (Color) The Dante spectrum for the experiment (black), HF model (red), and Nova model (blue) at the peak of the drive for an ignition-scale hohlraum driven with a 1.0MJ laser drive (shot N091204). 


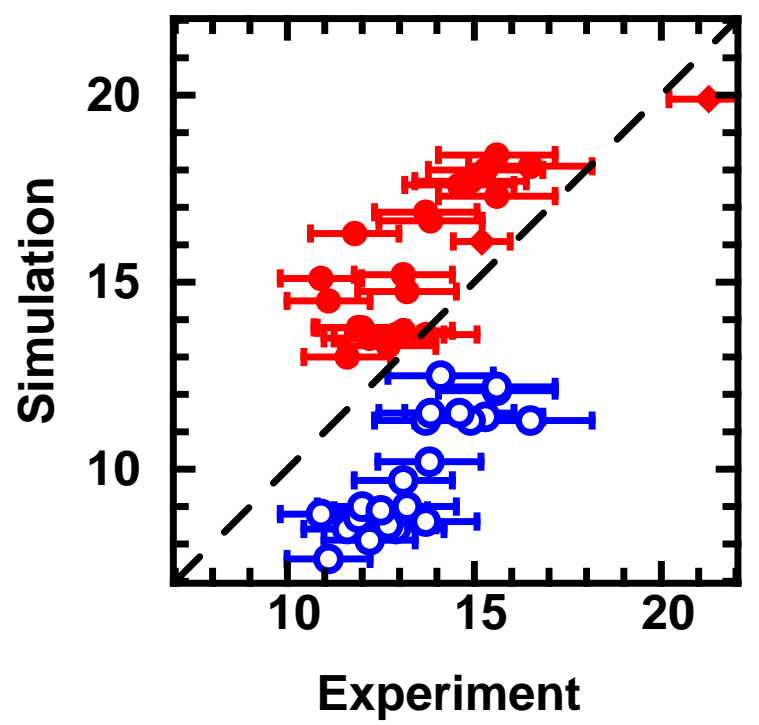

FIG. 5: (Color online) The simulated peak x-ray preheat fraction from the Nova model (blue open circles) and the HF model (red filled circles) against the experimental peak x-ray preheat fraction. Also shown, as red diamonds, are the HF model's simulations for the 2010 experiments. The experimental error bar is $\pm 10 \%$

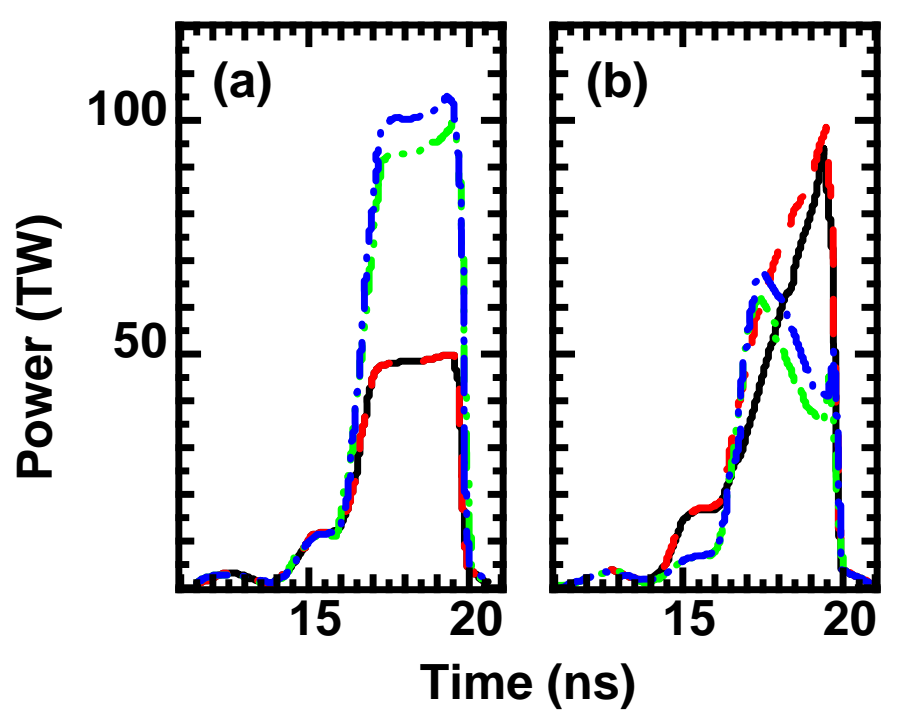

FIG. 6: (Color online) The time history of the $23.5^{\circ}$ (solid black line), $30^{\circ}$ (dashed red line), $44.5^{\circ}$ (dash-dot-dot green line), and $50^{\circ}$ (dash-dot line) quads before (a) and after (b) cross-beam amplification and backscatter removal for the recent 1.0MJ shot N101004 with $\Delta \lambda=8.5 \AA$. 


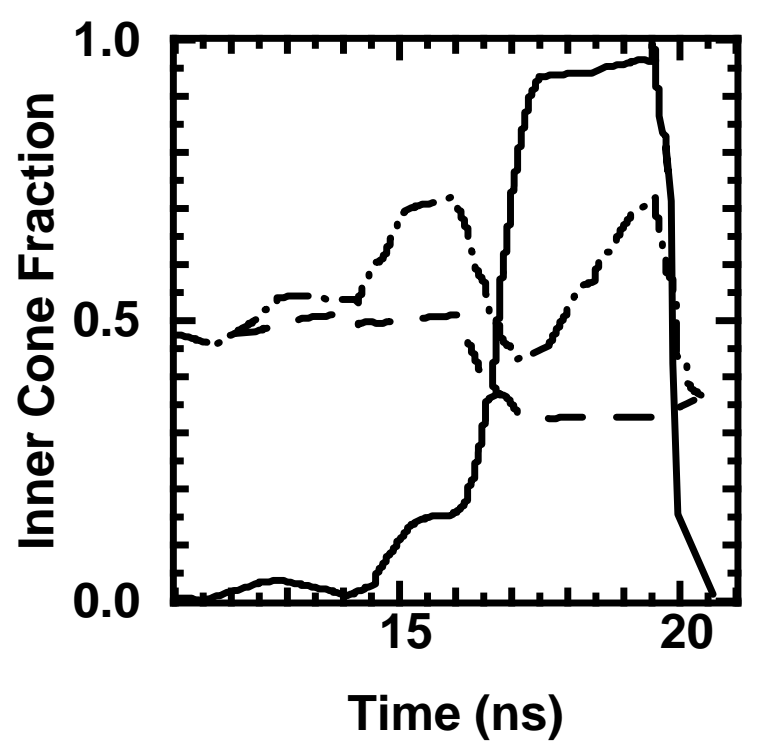

FIG. 7: The inner cone fraction for the incident laser pulse (dashed line) and the laser power generated with power transfer and backscatter removed (dash-dot line) for the 1.0MJ shot N101004 with $\Delta \lambda=8.5 \AA$. The total laser pulse is shown as the solid line. The average inner cone fraction over the peak of the laser pulse rises from an input fraction of $33 \%$ to $57 \%$.

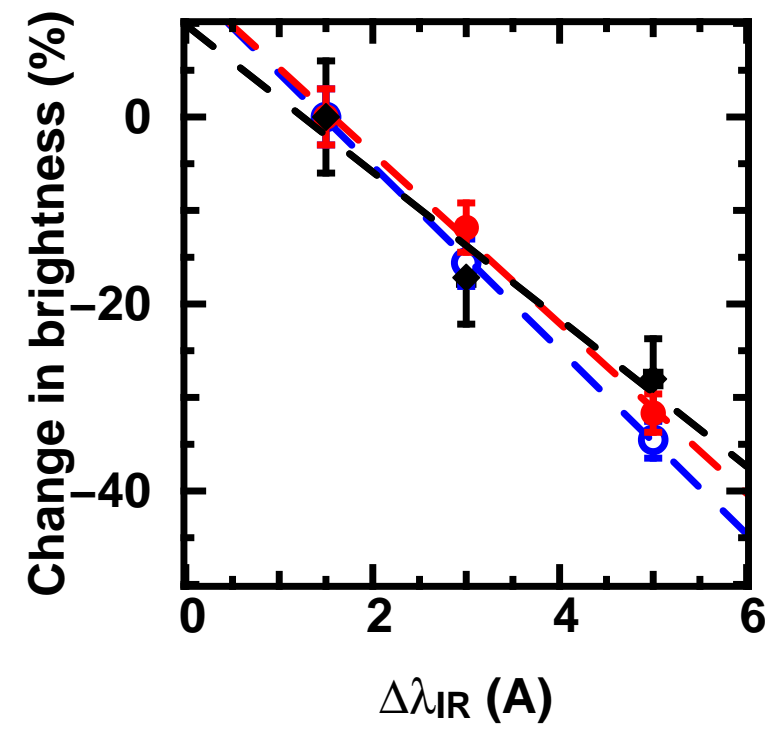

FIG. 8: (Color online) The change in the x-ray brightness of the wall emission attributed to the outer laser quads for the experiment (black squares), Nova-model (blue open circles) and HF model (red filled circles). 


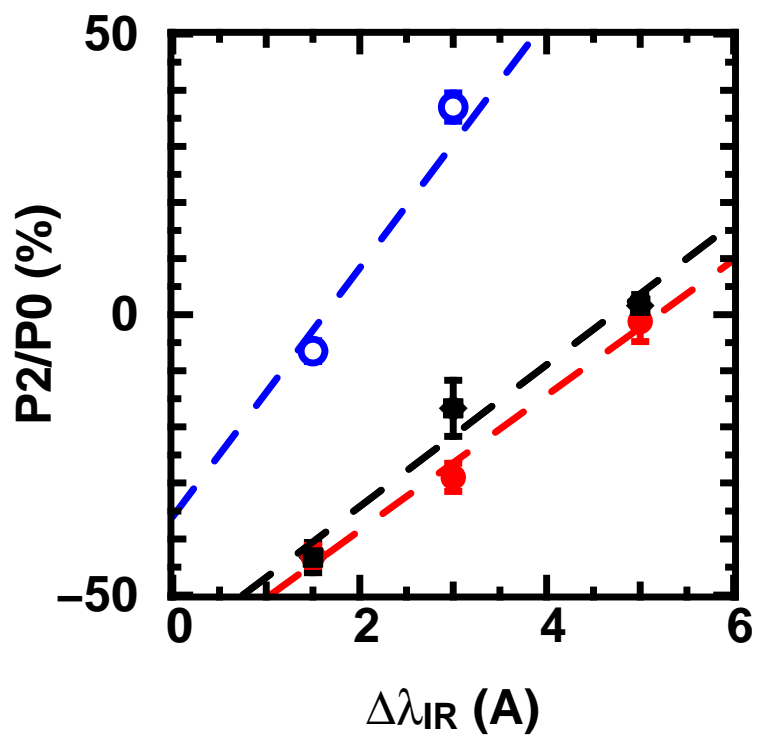

FIG. 9: (Color online) The change in the P2/P0 of the $17 \%$ contour of the emission from the imploded capsule for the experiment (black squares), Nova-model (blue open circles) and HF model (red filled circles).

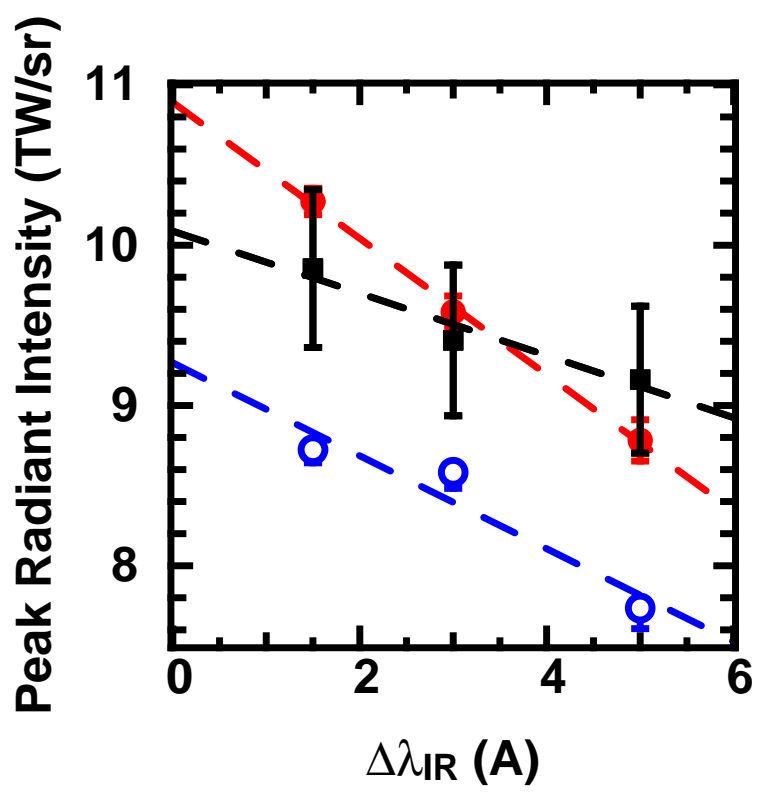

FIG. 10: (Color online) The change in the peak x-ray radiant intensity measured by Dante as a function of $\Delta \lambda$ for the experiment (black squares), Nova-model (blue open circles) and HF model (red filled circles). 


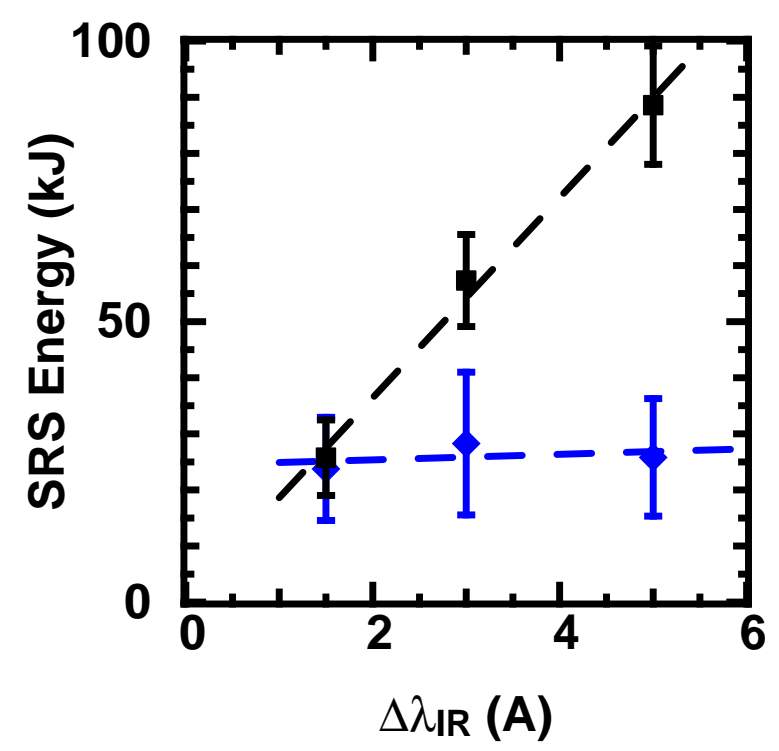

FIG. 11: (Color online) The $30^{\circ}$ quad SRS backscatter (blue diamonds) and total SRS energy inferred from the hot electron measurement (black squares) as a function of $\Delta \lambda$.

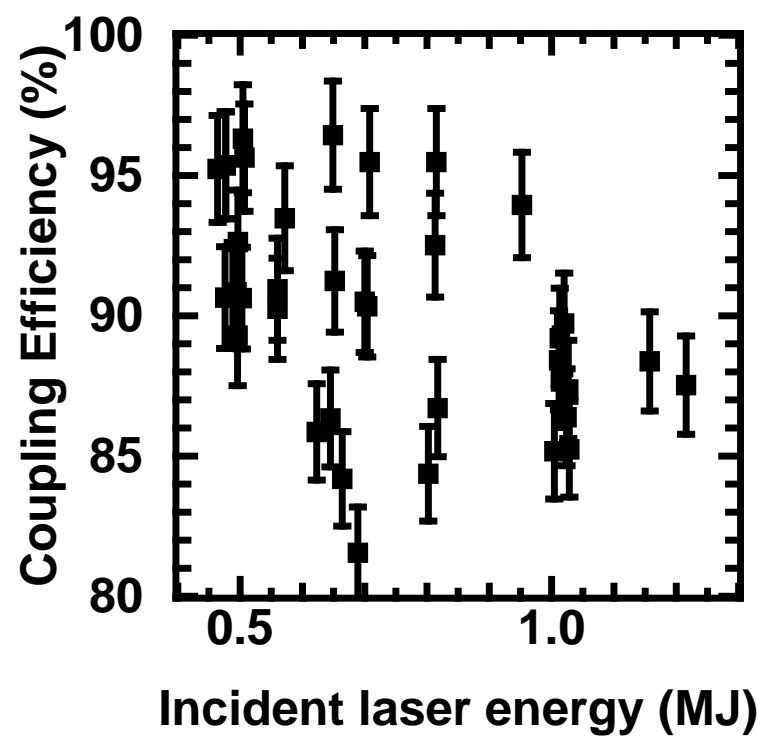

FIG. 12: The coupling efficiency of laser energy into the hohlraum as a function of incident laser energy. 